of

\title{
Photoelectric Bacteria Enhance the in situ Production of Tetrodotoxin for Antitumor Therapy
}

Xia-Nan Wang§, Mei-Ting Niu§, Jin-Xuan Fan, Qi-Wen Chen, and Xian-Zheng Zhang*

Key Laboratory of Biomedical Polymers of Ministry of Education \& Department of Chemistry, Wuhan University, Wuhan 430072, P. R. China

* Corresponding author. E-mail address: xz-zhang@whu.edu.cn (X.-Z. Zhang).

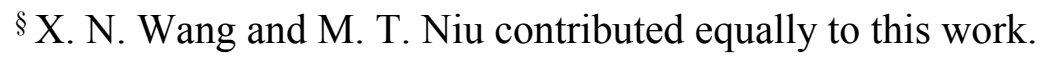




\section{Experimental Section}

Materials: Chloroauric acid $\left(\mathrm{HAuCl}_{4}\right)$ was purchased from Bide Pharmatech Co., Ltd. (Shanghai, China). Sodium lactate and TTX were purchased from Aladdin Reagents Co., Ltd. Agar and 2216E liquid medium were purchased from Guangdong Huankai Microbial SCI \& Tech Co., Ltd. TTX Elisa kit was purchased from YaJi Biological Co., Ltd. (Shanghai, China). Amplite ${ }^{\mathrm{TM}} \mathrm{NAD}^{+} / \mathrm{NADH}$ assay kit was purchased from Beyotime Biotechnology Co., Ltd. LIVE/DEAD® BacLight Bacterial Viability Kits was purchased from Molecular Probes Co., Ltd. Roswell Park Memorial Institute (RPMI) 1640 medium, fetal bovine serum (FBS), and trypsin were provided by Invitrogen (USA). 2',7'-dichlorofluorescin diacetate (DCFH-DA) were obtained from Beyotime Institute of Biotechnology (China). 3-[4,5-Dimethylthiazol-2yl]-diphenyltetrazolium-bromide (MTT) was supplied by Beyotime Biotechnology Co. Ltd. Dimethyl sulfoxide (DMSO) was purchased from Aladdin Reagents Co., Ltd. 1,1-dioctadecyl3,3,3,3-tetramethylindotricarbocyanine iodide (DiR iodide) and Cy5 were purchased from Beyotime Biotechnology Co. Ltd. All other reagents were used as received and without further purification.

Characterization: Transmission electron microscopy (TEM) images were obtained by JEM2100 (JEOL) transmission electron microscope. The UV-vis absorbance was measured by UVvis spectroscopy (Lambda Bio40). XPS was recorded with a Thermo Fisher ESCALAB 250Xi multi-technique surface analysis instrument. XRD analysis was performed with a Rigaku MiniFlex600 X-ray diffractometer. Zeta potential and particle size were studied using a zeta sizer (Nano ZS, Malvern Instruments). 660nm laser (STL808T1-7.0 W, Beijing STONE Laser) was performed for evaluating photothermal property and thermal imaging was recorded by FLIR Ax5 camera (FLIR Systems AB, Sweden). Live/dead bacterial viability assay was carried out by fluorescence inverted microscope (Olympus IX73P2F). The generation of intracellular ROS were evaluated through DCFH-DA indicator by fluorescence inverted microscope (Olympus IX73P2F). The cell viability was measured using microplate reader (Bio-Rad, 
Blood routine was examined by Auto Hematology Analyzer (MC 6200VET) and blood biochemistry analysis was measured by biochemical auto analyzer (MNCHIP, Tianjin, China). In vivo imaging was detected by Spectrum Pre-clinicalIn Vivo Imaging System (PekinEmer). The CT signals of Au element was collected by a Quantum FX microCT system (PerkinElmer). Bacteria and culture condition: S. algae K3259 (GDMCC 1.341) was obtained from China Center for Type Culture Collection (CCTCC). S. algae was aerobically incubated in 2216E liquid medium (5 $\mathrm{g} \mathrm{L}^{-1}$ peptone, $1 \mathrm{~g} \mathrm{~L}^{-1}$ yeast extract, $0.01 \mathrm{~g} \mathrm{~L}^{-1}$ ferric phosphate) with shaking for $12 \mathrm{~h}$ at $28{ }^{\circ} \mathrm{C}$. To optimize the fermentation condition, the medium was added $0.1 \%$ peptone, $2.5 \%$ yeast extract and regulated the $\mathrm{pH}$ to 7.5 .

Synthesis of Bac@Au and Bac@Au (large): S. algae was collected from an overnight 2216E liquid medium by centrifuging at $6000 \mathrm{rpm}$ for $3 \mathrm{~min}$ and washed by $4 \mathrm{~mL}$ PBS solution for three times. The washed bacteria were resuspended in $2 \mathrm{~mL}$ PBS solution, with a final $\mathrm{OD}_{600}$ of $0.5 \pm 0.2$. Then $100 \mu \mathrm{L} \mathrm{HAuCl}_{4}(50 \mathrm{mM})$ and $20 \mu \mathrm{L}$ sodium lactate $(73 \%)$ were dissolved into the bacterial suspension. After the mixture was incubated at $28^{\circ} \mathrm{C}$ for 1 h, Bac@Au was obtained. Prolonging the incubation time to 4 h, Bac@Au (large) was obtained.

Electrochemical measurement: Photocurrent of Bac@Au was studied by an electrochemical analysis system (CHI830, Chenhua Instruments, Shanghai, China) with a standard threeelectrode system consisted of a platinum electrode, a saturated calomel electrode (SCE) and a modified glassy carbon electrode (GCE) (3 mm in diameter) working electrode. The modified GCE working electrode was prepared by coating carbon cloth. A piece of acid-treated $\left(\mathrm{H}_{2} \mathrm{SO}_{4} / \mathrm{HNO}_{3}, 3: 1\right)$ carbon cloth $\left(1 \times 1 \mathrm{~cm}\right.$, projected area $\left.2 \mathrm{~cm}^{2}\right)$ was placed into a PE tube and soaked with the Bac@Au suspension $\left(10^{8} \mathrm{CFU} \mathrm{mL}-1\right)$ which was dispersed in PBS solution, then stored at $4{ }^{\circ} \mathrm{C}$ for $24 \mathrm{~h}$ to make a firm attachment of Bac@Au and carbon cloth. The $0.1 \mathrm{M}$ $\mathrm{Na}_{2} \mathrm{SO}_{4}$ solution was served as electrolyte. An $18 \mathrm{~W}$ LED lamp was used as the light source. Bac and Bac@Au (large) were repeated the same operation as control.

Photothermal measurement: Bac@Au (large) suspension $\left(10^{8} \mathrm{CFU} \mathrm{mL}^{-1}\right)$ placed in $5 \mathrm{~mL}$ glass 
tube was irradiated by $660 \mathrm{~nm}$ laser $\left(30 \mathrm{~mW} \mathrm{~cm}^{-2}\right)$ with different times and the temperature imaging was recorded by FLIR Ax5 camera. Bac and Bac@Au were repeated the same operation as control.

TTX detection: TTX produced by bacteria was detected by Tetrodotoxin Elisa kit. Collected Bac@Au was resuspended in fresh medium $\left(10^{9} \mathrm{CFU} \mathrm{mL} \mathrm{m}^{-1}\right)$ and irradiated by $660 \mathrm{~nm}$ laser with different times. Four hours after the irradiation, the medium containing Bac@Au was collected to lyse bacteria by ultrasonication. $50 \mu \mathrm{L}$ ultrapure water (as blank control), TTX standard and samples were added respectively into every well and incubated at $37^{\circ} \mathrm{C}$ for $1 \mathrm{~h}$. Then the supernatant was drained clearly and all wells were washed with ultrapure water for three times. TTX reactant mixture was added into all wells and incubated in darkness for 15 min to dye. The absorbance at $450 \mathrm{~nm}$ was measured by microplate reader.

$\mathrm{NAD}^{+} / \mathrm{NADH}$ detection: $\mathrm{NAD}^{+} / \mathrm{NADH}$ content was detected by Amplite $^{\mathrm{TM}} \mathrm{NAD}^{+} / \mathrm{NADH}$ assay kit. Collected Bac@Au was resuspended in fresh medium $\left(10^{9} \mathrm{CFU} \mathrm{mL}^{-1}\right)$ and irradiated by $660 \mathrm{~nm}$ laser with different times. Four hours after the irradiation, the medium containing Bac@Au was collected and dissolved with protease inhibitor. Bac@Au was harvested by centrifuging (590 g, $5 \mathrm{~min})$ at $4{ }^{\circ} \mathrm{C}$ and washed with PBS for twice. Then Bac@Au was resuspended with lysis buffer and oscillated at $4{ }^{\circ} \mathrm{C}$ for $30 \mathrm{~min}$. The lysate was harvested by centrifuging (590 g, $5 \mathrm{~min}$ ) at $4{ }^{\circ} \mathrm{C}$. Operation solution (ethanol dehydrogenase) was added into every well of blank control, standard and samples and incubated at $37^{\circ} \mathrm{C}$ in darkness for 10 min. TMB substrate was added into every well for incubating $30 \mathrm{~min}$ in darkness and the absorbance at $450 \mathrm{~nm}$ was measured by microplate reader.

Photoelectrons transfer efficiency: The photoelectrons transfer efficiency in this paper is defined by the ratio of electrons effective electrons used in $\mathrm{NAD}^{+} / \mathrm{NADH}$ transition to the total input photo flux.

$$
\mathrm{QE} \%=\frac{\text { electrons }}{\text { photons }} \times 100 \%=\frac{\text { mol NADH generated }}{\text { mol total photons }} \times 100 \%
$$


Where

mol NADH generated $=$ the increasing NADH concentration $(\mathrm{NADH}) \times$ total suspension volume $(\mathrm{V})$

mol total photons $=$ photo flux $\left(\Phi\right.$ ph $\left.\mathrm{cm}^{-2} \mathrm{~s}^{-1}\right) \times$ area of irradiation $(\mathrm{A}) \times$ reaction time $(\mathrm{t}) /$ Avogadro's Number $\left(\mathrm{N}_{\mathrm{A}}\right)$

Therefore, the $\mathrm{QE} \%$ can be rewritten as:

$$
\mathrm{QE} \%=\frac{N A D H \times V \times \mathrm{N}_{A}}{\Phi \operatorname{ph} \times \mathrm{t} \times \mathrm{A}} \times 100 \%
$$

The following calculation example is based on the data after 3 min irradiation.

$\mathrm{NADH}=2 \mu \mathrm{M} \quad \mathrm{V}=1 \mathrm{~mL} \quad \mathrm{~N}_{\mathrm{A}}=6.022 \times 10^{23}$

Photons (660 nm laser): $\Phi \mathrm{ph}=6.04 \times 1010 \mathrm{~cm}^{-2} \mathrm{~s}^{-1} \quad \mathrm{t}=3 \min \times 60=180 \mathrm{~s} \quad \mathrm{~A}=\Pi \times$ $1.52 \mathrm{~cm}^{2}=7.065 \mathrm{~cm}^{2}$

$\mathrm{NADH} \times \mathrm{V} \times \mathrm{N}_{\mathrm{A}}=2 \times 10^{-6} \times 1 \times 10^{-3} \times 6.022 \times 10^{23}=1.2044 \times 10^{15}$

$\Phi$ ph $\times \mathrm{t} \times \mathrm{A}=1.5 \times 10^{14} \times 180 \times 7.065=1.907 \times 10^{17}$

$$
\mathrm{QE} \%=\frac{N A D H \times V \times \mathrm{NA}}{\Phi \operatorname{ph} \times \mathrm{t} \times \mathrm{A}}=\frac{1.2044 \times 10^{15}}{1.907 \times 10^{17}}=0.63 \%
$$

Live and dead bacteria straining assay: The observation of live and dead bacteria was performed by LIVE/DEAD® BacLight Bacterial Viability Kits. SYTO 9 stain and propidium iodide (PI) stain were mixed by 1:1, then added into Bac@Au suspension (3 $\mu \mathrm{L}$ mixed stain with $10^{9} \mathrm{CFU} \mathrm{mL}-1$ bacteria) and incubated at $37^{\circ} \mathrm{C}$ for $15 \mathrm{~min}$ in darkness. Then the suspension was washed with PBS three times and centrifuged at 6000 rpm. Dyed Bac@Au was resuspended in PBS and drop onto the glass slide, finally observed by inverted microscope.

Cell line and culture condition: CT26 mouse colon carcinoma cells (ATCC CRL-2638) and 4T1 murine breast cancer cells (ATCC-CRL-2539), were obtained from China Center for Type Culture Collection (CCTCC). Both CT26 cells and 4T1 cells were respectively cultured in RPMI 1640 medium with 10\% FBS and 1\% antibiotics (penicillin-streptomycin, $10000 \mathrm{U}$ 
$\left.\mathrm{mL}^{-1}\right)$

ROS generation in vitro: The intracellular ROS was evaluated through DCFH-DA indicator by fluorescence microscope. CT26 cells were seeded in confocal dishes and cultured for $24 \mathrm{~h}$ at $37{ }^{\circ} \mathrm{C}$ in $5 \% \mathrm{CO}_{2}$. Then $\mathrm{CT} 26$ cells were treated with TTX with different concentration $\left(10^{-1}\right.$, $10^{-2}, 10^{-3}, 10^{-4}, 10^{-5} \mathrm{mg} / \mathrm{mL}$ ) for $3 \mathrm{~h}$. Next, the cells were washed with PBS for three times, then stained by DCFH-DA $(10 \mu \mathrm{M})$ diluted in serum-free medium for $20 \mathrm{~min}$. Next, the cells were washed three times with serum-free medium and observed by fluorescence microscope.

Cytotoxicity assay: The cytotoxicity of cell in vitro was measured by the MTT assay. CT26 cells and 4T1 cells were seeded in 24-well plates $\left(5 \times 10^{4}\right.$ cells per well $)$ and cultured in RPMI 1640 medium $(0.5 \mathrm{~mL}$ per well) containing $10 \%$ FBS for $24 \mathrm{~h}$. Then transwell chambers were placed every well and $100 \mu \mathrm{L} 1640$ medium was supplemented for immersing the chambers. Bac@Au with different concentration $\left(10^{6}, 10^{7}, 10^{8}, 10^{9}, 10^{10} \mathrm{CFU} \mathrm{mL}^{-1}\right)$ and other groups (as shown in Figure 3C) was resuspended into 2216E liquid medium and added into chambers. Then the cells were irradiated by $660 \mathrm{~nm}$ laser $\left(30 \mathrm{~mW} \mathrm{~cm}{ }^{-2}, 3 \mathrm{~min}\right)$ and incubated in a humidified atmosphere containing $5 \% \mathrm{CO}_{2}$ at $37{ }^{\circ} \mathrm{C}$ for $4 \mathrm{~h}$ in darkness, removed the chambers and continued incubating in a humidified atmosphere containing $5 \% \mathrm{CO}_{2}$ at $37{ }^{\circ} \mathrm{C}$ for $24 \mathrm{~h}$ in darkness. Then the cells medium was refreshed and $50 \mu \mathrm{L}$ MTT $\left(5 \mathrm{mg} \mathrm{mL}^{-1}\right)$ was added into each well and co-incubated for another $4 \mathrm{~h}$. The supernatant was drained carefully and $750 \mu \mathrm{L}$ of DMSO was added into each well. Precipitation was dissolved completely and the absorbance at $570 \mathrm{~nm}$ of the mixture was measured by microplate reader. Relative cell viability of the calculated according to the formula:

Cell viability $(\%)=\left(\mathrm{OD}_{570 \text { sample }} \mathrm{OD}_{570 \text { blank }}\right) /\left(\mathrm{OD}_{570 \text { control }} \mathrm{OD}_{570 \text { blank }}\right) \times 100 \%$

Establishment the model of subcutaneous tumor bearing Balb/c mice: All the animal experiments were implemented in line with the guidelines for laboratory animals established by the Wuhan University Center for Animal Center Experiment/A3-Lab. And all the animal 
experiments were obeyed the approval by the Institutional Center of Wuhan University (Wuhan, China). CT26 cells (100 $\mu \mathrm{L}, 10^{7}$ cells $\left.\mathrm{mL}^{-1}\right)$ were subcutaneously injected into the right flank of female Balb/c mice, the weight of which was 16-18g.

In vivo biotoxicity evaluation: The physiological effects caused by Bac@Au were assessed by blood biochemistry and blood routine examination in vivo respectively. Another 12 female Balb/c mice were divided into 4 groups randomly, which were injected intravenously with Bac@Au+Laser, Bac@Au, Bac and PBS respectively $(n=3)$. After 1 day of post exposure, the blood (100 $\mu \mathrm{L}$ each mouse) were collected from heart for testing the blood biochemistry and blood routine indexes. To evaluate the systemic inflammation and infection caused by $S$. algae, a mouse CRP ELISA kit and a PCT ELISA kit were used to test mouse plasma concentrations of CRP and PCT.

In vivo imaging: When the volume of tumors was reached approximate 150 mm³ $^{3}$, Bac@Au and Bac were respectively labeled with Cy5 and injected intravenously. Briefly, $10 \mu \mathrm{L} \mathrm{Cy} 5$ solution $(1 \mu \mathrm{M})$ was dissolved in DMSO and added into bacterial suspension $\left(\mathrm{OD}_{600}=0.5\right)$, and incubated at $37^{\circ} \mathrm{C}$ for $15 \mathrm{~min}$. Then dyeing Bac@Au or Bac was obtained by washing with PBS three times and centrifuging at $6000 \mathrm{rpm}$ to remove unbound dye and finally injected intravenously into mice ( $100 \mu \mathrm{L} \mathrm{OD}_{600}=0.5$ per mouse). The mice were anesthetized and observed by IVIS imaging systems at different time points $(0,2,4,8,12,24,48,72,96$ h). Cy5: $\mathrm{Ex}=650 \mathrm{~nm}, \mathrm{Em}=670 \mathrm{~nm}$.

In vivo CT imaging: When the volume of tumors was reached approximate $150 \mathrm{~mm}^{3}$, Before and 24 h after Bac@Au and Bac $\left(100 \mu \mathrm{L}, 2 \times 10^{7} \mathrm{CFU} \mathrm{mL}^{-1}\right.$ per mouse) were respectively intravenous injected into CT26 tumor mice, collecting the CT signals by a Quantum FX microCT system (PerkinElmer).

Measurements of Au element in organs and tumors: When the volume of tumors was reached approximate $150 \mathrm{~mm}^{3}$, Bac@Au and Bac $\left(100 \mu \mathrm{L}, 2 \times 10^{7} \mathrm{CFU} \mathrm{mL}^{-1}\right.$ per mouse) were respectively intravenous injected into CT26 tumor mice. After $24 \mathrm{~h}$, the mice were sacrificed 
and tumors as well as main organs (heart, liver, spleen, lung, kidney) were all harvested and boiled with aqua regia (Nitric acid: Hydrochloric acid=1:3) until the tissue becoming clear and transparent liquid. Then the liquid was tested by ICP-MS to quantitative detect the Au element. In vivo biodistribution study: To evaluate long-term distribution in vivo, Bac@Au and Bac were respectively labeled with Cy5 dye $(0.1 \%, v / v)$ and washed with PBS three times, separated by centrifuging and injected into mice $\left(100 \mu \mathrm{L} \mathrm{OD}_{600}=0.5\right.$ per mouse). After $24 \mathrm{~h}$, the mice were sacrificed and their main organs (heart, liver, spleen, lung, kidney) and tumors were dissected and collected for fluorescence imaging analyses. For further quantitative analysis of bacterial population, the isolated organs and tumor were homogenate in $1 \mathrm{~mL}$ PBS containing $0.1 \%$ Triton X-100 by grinding. The homogenate was serial diluted to plate on solid 2216E plates with $24 \mathrm{~h}$ incubation at $37^{\circ} \mathrm{C}$. The pictures of bacterial colonies on the plates were taken. To observe the distribution in vivo more clearly, the organs and tumor were immersed in tissue fixative solution 1 day and sliced up for FISH fluorescence staining and gram staining. In vivo antitumor treatment: When the volume of tumors was reached approximate $150 \mathrm{~mm}^{3}$, CT26 subcutaneous tumor bearing mice were divided into seven groups randomly in different treatments as shown in Figure 6B: 1) Bac@Au + Laser $\left(2 \times 10^{7} \mathrm{CFU} \mathrm{mL}^{-1}, 660 \mathrm{~nm}\right.$ laser, 30 mW cm $\left.\left.{ }^{-2}, 3 \mathrm{~min}\right), 2\right)$ Bac@Au $\left.\left(2 \times 10^{7} \mathrm{CFU} \mathrm{mL}^{-1}\right), 3\right) S$. algae $\left.\left(2 \times 10^{7} \mathrm{CFU} \mathrm{mL}^{-1}\right), 4\right) S$. oneidensis $\left.\left(2 \times 10^{7} \mathrm{CFU} \mathrm{mL}^{-1}\right), 5\right) \mathrm{TTX}(1 \mathrm{ng}$ per mouse $\left.), 6\right) \mathrm{d}-S$. algae, 7) PBS. And other two groups: Laser and intratumorally injected Dead Bac@Au + Laser were added. To keep the property of s-AuNPs biosynthesized by $S$. algae, Bac@Au was lysed to obtained the Dead Bac@Au. Each group was injected intravenously respectively every other day for three times. The tumor volume and body weight of mice were recorded every two days. The tumor sizes were calculated as (tumor width) $)^{2} \times($ tumor length) $/ 2$. After 16 days, the mice were sacrificed and tumors were excised, and main organs (heart, liver, spleen, lung, kidney) were all harvested for pathological and biochemical analyse.

Statistical Analysis: All statistical analyses were performed on SPSS (version 22) or Graphpad 
Prism 7. For cell experiments and in vivo experiments, investigators performing operations were blinded to treatment groups. In in vivo experiments, animals were randomly divided into different groups. 
Table S1. Zeta potential of Bac and Bac@Au

\begin{tabular}{cc}
\hline Sample & Zeta potential $(\mathrm{mV})$ \\
\hline Bac & $-30.3 \pm 2.8$ \\
Bac@Au & $-23.9 \pm 0.3$ \\
\hline
\end{tabular}


Table S2. Au element content in Bac@Au prepared in different concentration of $\mathrm{HAuCl}_{4}$ and Au element content in Bac@Au after cocultured with serum.

\begin{tabular}{cc}
\hline Sample $\left(10^{9} \mathrm{CFU}\right)$ & Au element content $(\mu \mathrm{g})$ \\
\hline Bac & $0.0425 \pm 0.003$ \\
Bac@Au $(1.25 \mu \mathrm{M})$ & $35.795 \pm 1.547$ \\
Bac@Au $(2.5 \mu \mathrm{M})$ & $67.525 \pm 1.823$ \\
Bac@Au $(5 \mu \mathrm{M})$ & $88.15 \pm 0.7933$ \\
Bac@Au $(2.5 \mu \mathrm{M}$ in serum $)$ & $57.55 \pm 1.2085$ \\
\hline
\end{tabular}




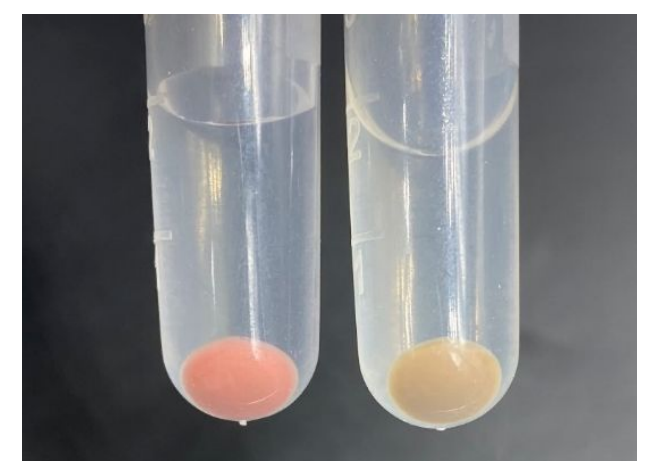

Figure S1. The photograph of Bac and Bac@Au collecting by centrifugation. 


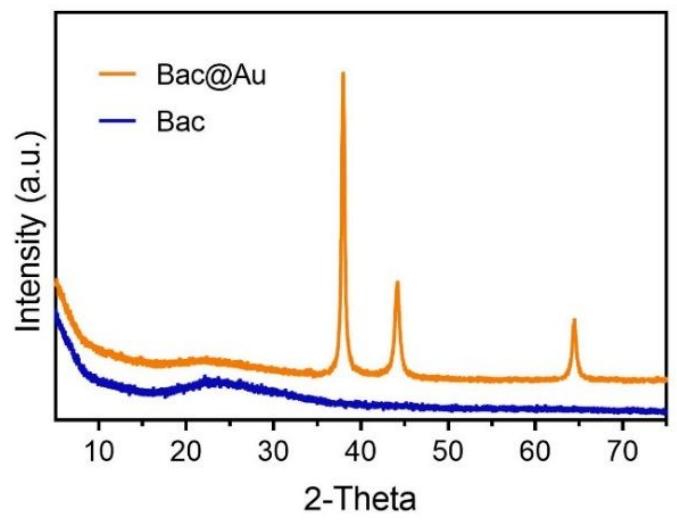

Figure S2. PXRD patterns of Bac and Bac@Au. 

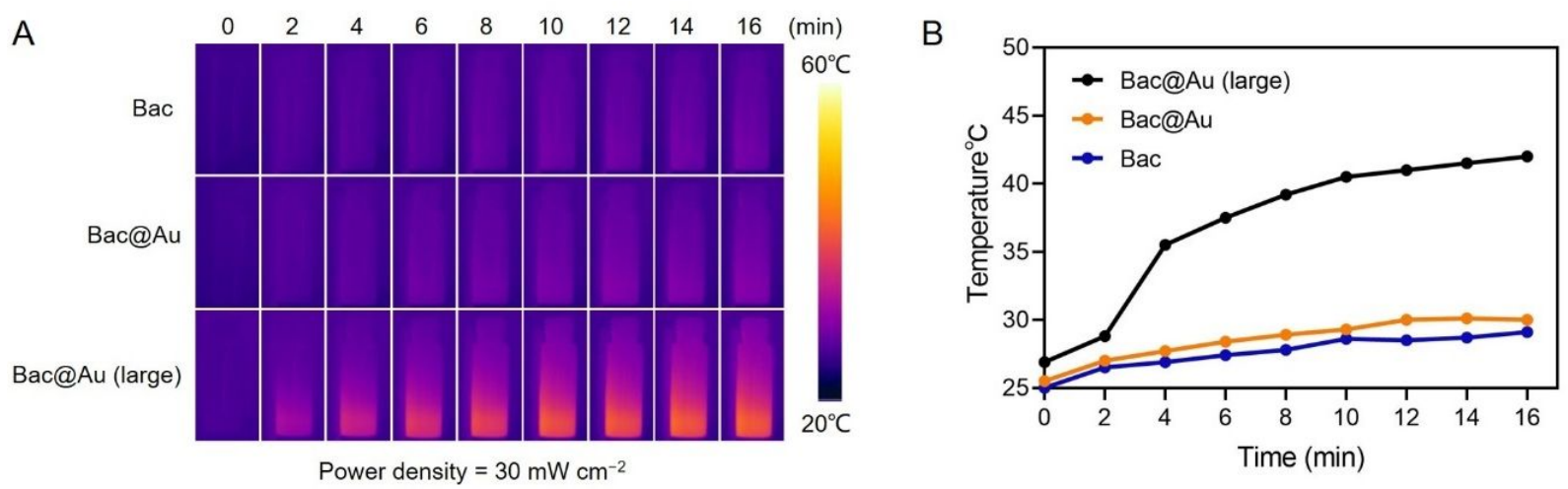

Figure S3. (A) Real-time thermal imaging of Bac, Bac@Au and Bac@Au (large) aqueous solutions under $660 \mathrm{~nm}$ laser irradiation (power density $=30 \mathrm{~mW} \mathrm{~cm}^{-2}$ ) and (B) corresponding temperature increasing profiles. 


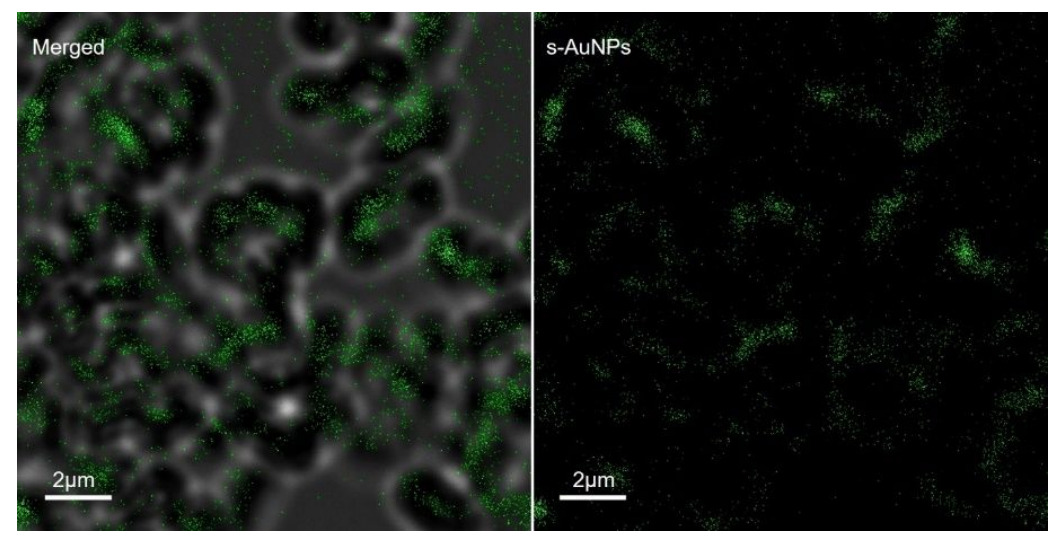

Figure S4. Confocal microscope imaging of Bac@Au excited at $545 \mathrm{~nm}$

for photoluminescence. 


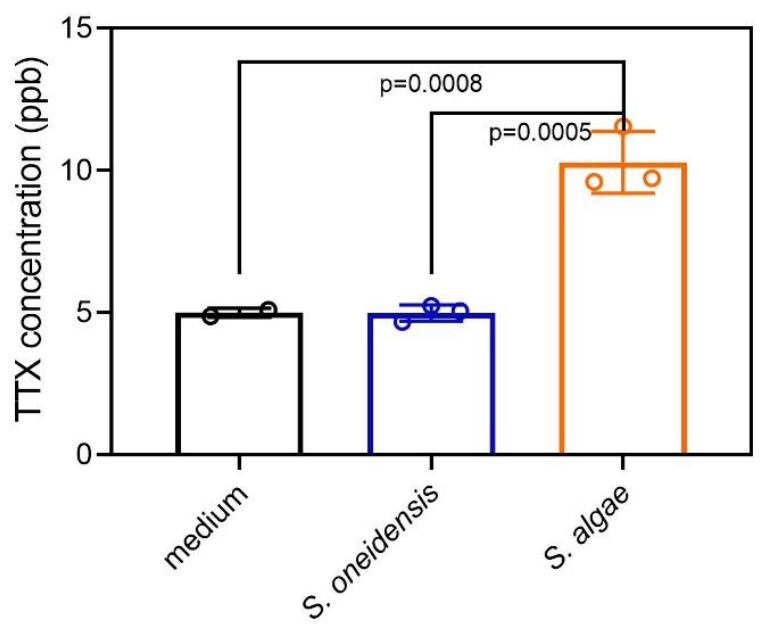

Figure S5. TTX concentration of bacterial culture medium, S. oneidensis and S. algae with the same bacterial concentration $\left(10^{10} \mathrm{CFU} \mathrm{mL}^{-1}\right)$. 


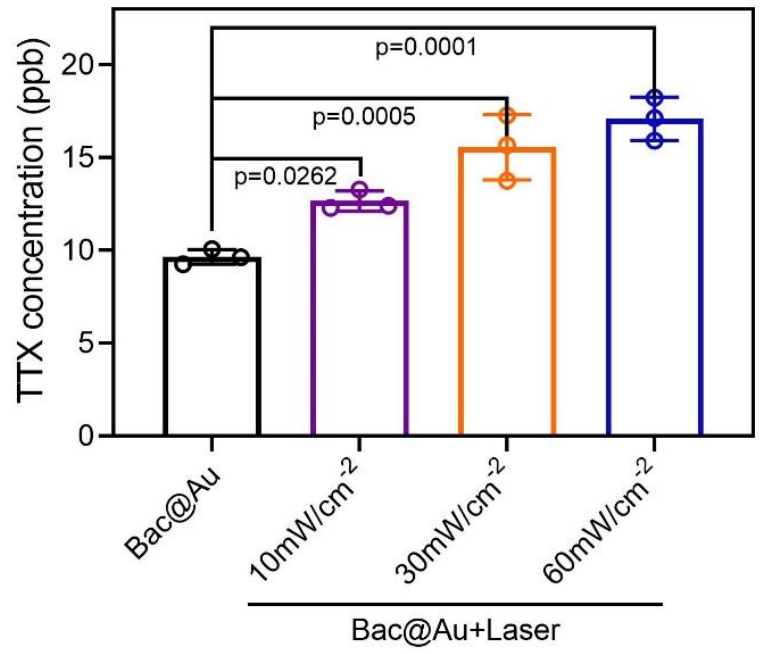

Figure S6. TTX concentration of Bac@Au and Bac@Au under 660 nm laser with different intensity $\left(10^{10} \mathrm{CFU} \mathrm{mL} \mathrm{m}^{-1}\right)$. 


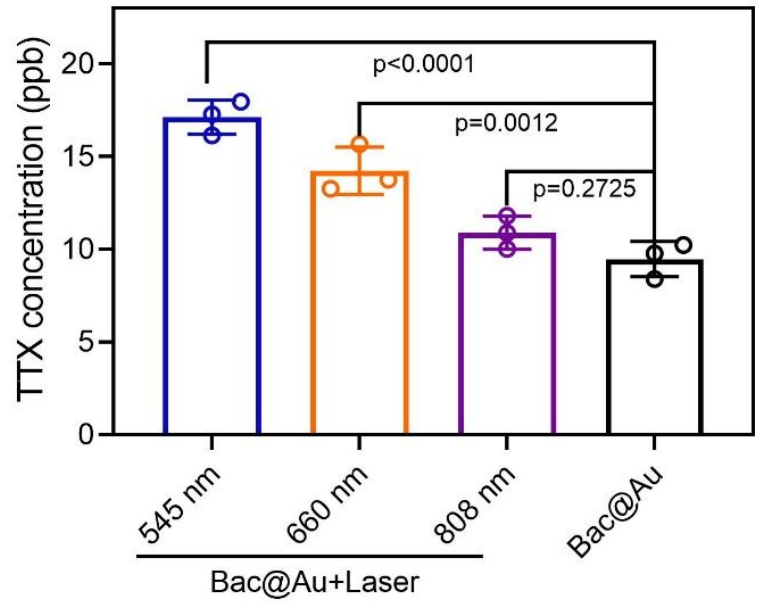

Figure S7. TTX concentration of Bac@Au and Bac@Au under laser with different wavelength and the same intensity $\left(10^{10} \mathrm{CFU} \mathrm{mL}-1\right)$. 


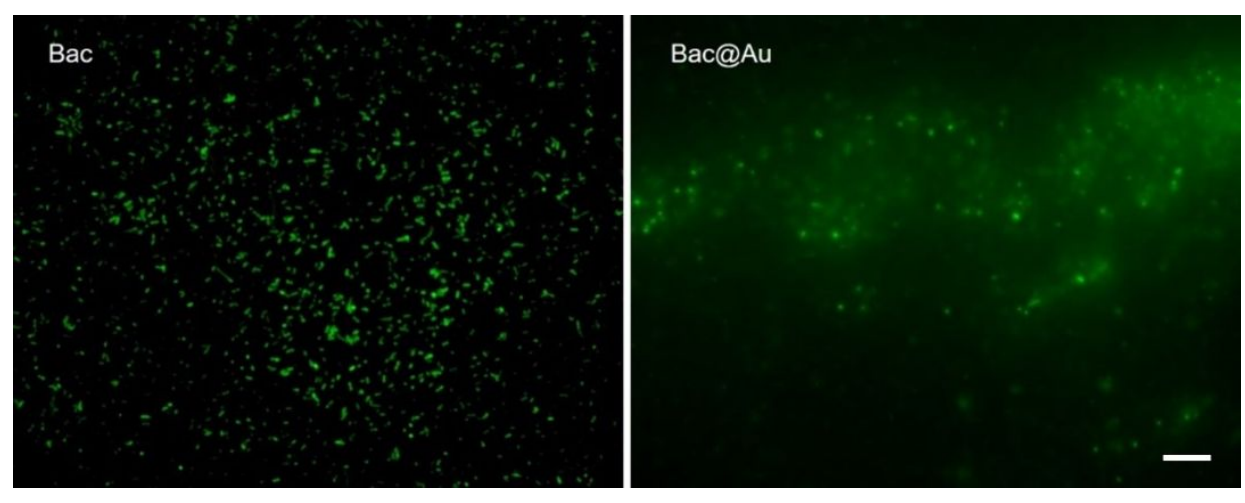

Figure S8. Microscope image of alive/dead bacteria staining (scale bar: $50 \mu \mathrm{m}$ ). 


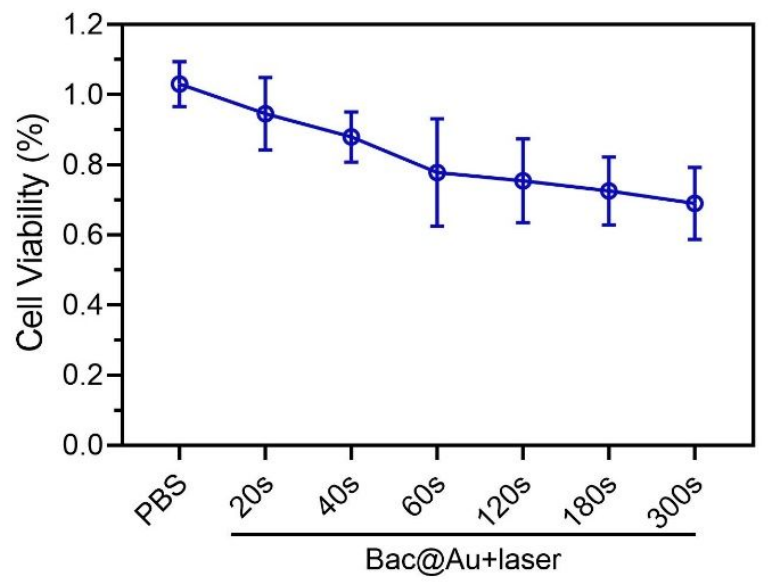

Figure S9. Cytotoxicity of Bac@Au irradiated under $660 \mathrm{~nm}$ laser $\left(\mathrm{CFU} / \mathrm{mL}=10^{9}\right.$, power density $\left.=30 \mathrm{~mW} \mathrm{~cm}^{-2}\right)$ with different times against CT26 cells $(\mathrm{n}=8)$. 


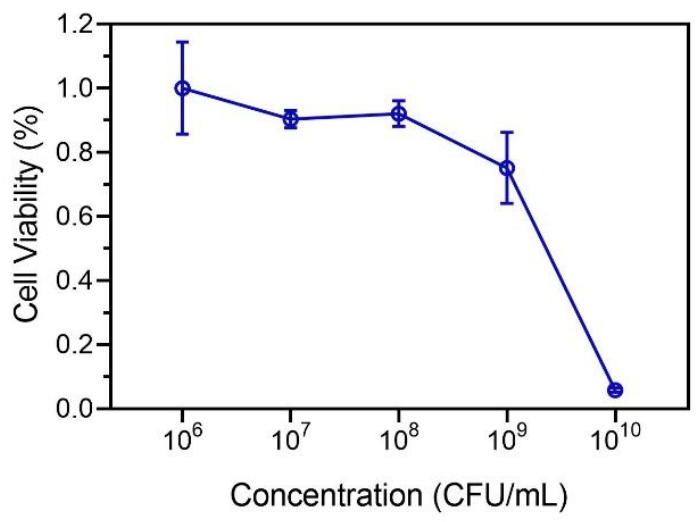

Figure S10. Cytotoxicity of Bac@Au with different bacterial concentration against CT26 cells under irradiation (power density $\left.=30 \mathrm{~mW} \mathrm{~cm}^{-2}, 3 \mathrm{~min}\right)(\mathrm{n}=8)$. 


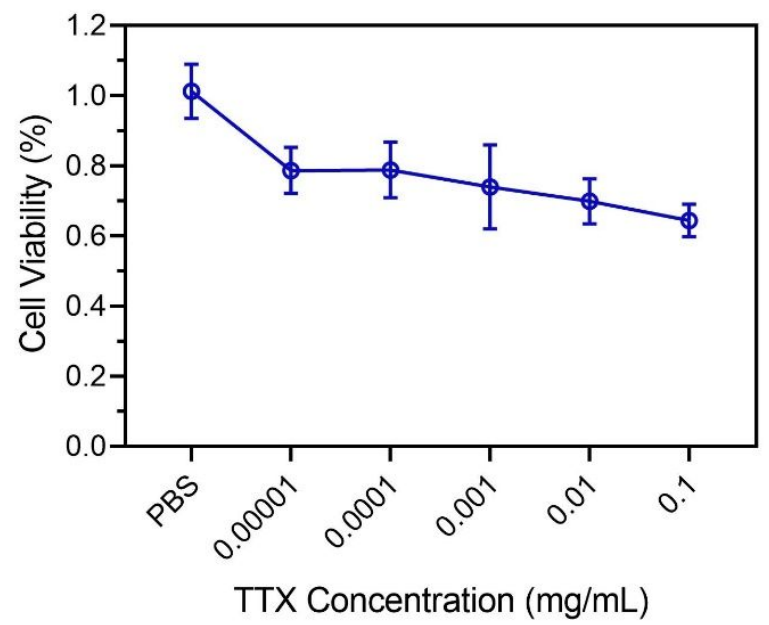

Figure S11. Cytotoxicity of TTX with different concentration against CT26 cells. $(n=8)$. 


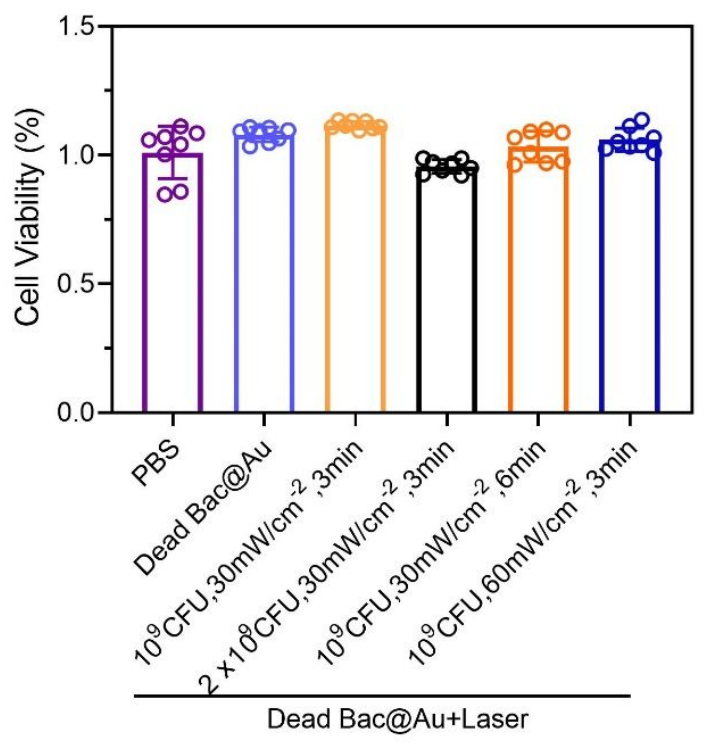

Figure S12. Cytotoxicity of Dead Bac@Au with different treatments against CT26 cells under irradiation From left to right: PBS, Dead Bac@Au, Dead Bac@Au + laser $\left(10^{9} \mathrm{CFU}, 30 \mathrm{~mW} / \mathrm{cm}^{-}\right.$ 2, 3min), Dead Bac@Au + laser (2 x1099FU, 30mW/cm², 3min), Dead Bac@Au + laser $\left(10^{9} \mathrm{CFU}, 30 \mathrm{~mW} / \mathrm{cm}^{-2}, 6 \mathrm{~min}\right)$, and Dead Bac@Au + laser $\left(10^{9} \mathrm{CFU}, 60 \mathrm{~mW} / \mathrm{cm}^{-2}, 3 \mathrm{~min}\right)(\mathrm{n}=8)$. The statistical significance was calculated via two-way ANOVA with Tukey's multiple comparisons test. 


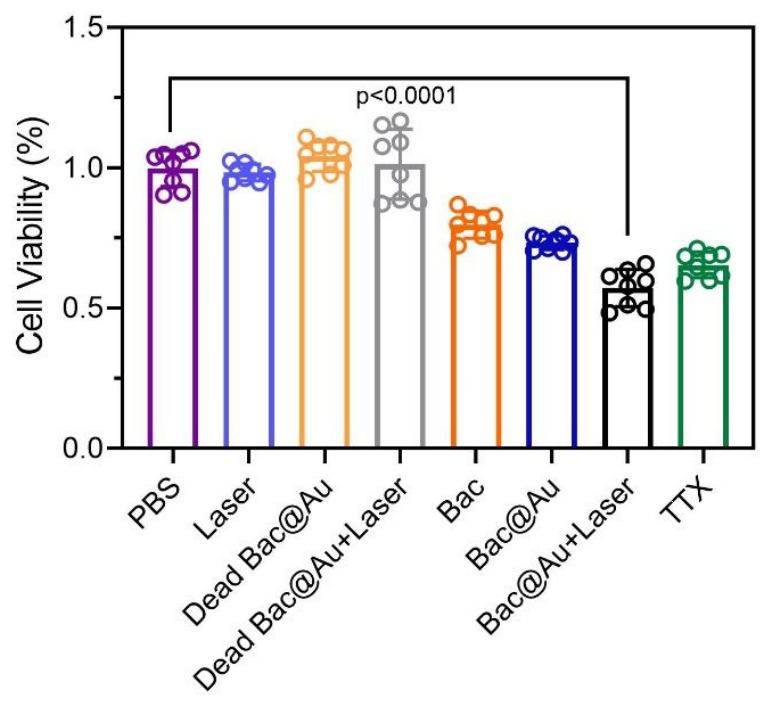

Figure S13. Cell viability of 4T1 cells in different treatments irradiated with $660 \mathrm{~nm}$ laser $\left(\mathrm{CFU} / \mathrm{mL}=10^{9}\right.$, power density $\left.=30 \mathrm{~mW} \mathrm{~cm}{ }^{-2}, 3 \mathrm{~min}\right)$. From left to right: PBS, laser, Dead Bac@Au, DeadBac@Au+ laser,Bac,Bac@Au,Bac@Au under irradiation, TTX (0.1mg/mL) $(\mathrm{n}=8)$. The statistical significance was calculated via two-way ANOVA with Tukey's multiple comparisons test. 


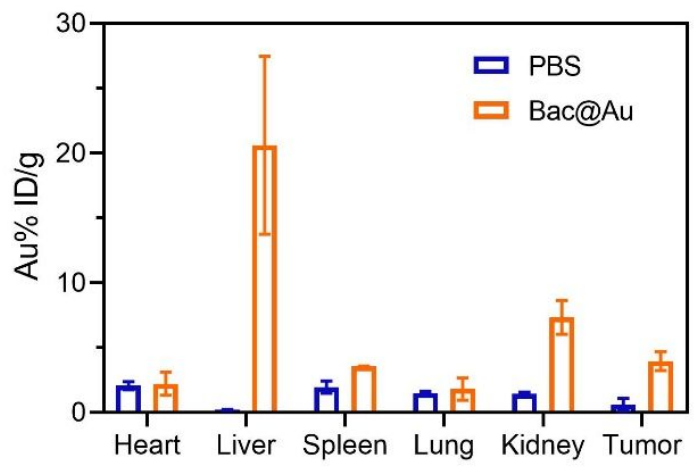

Figure S14. Au element content in organs after different treatments. 


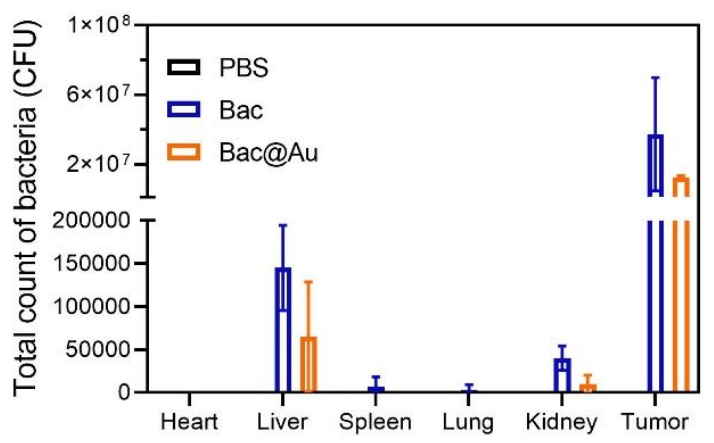

Figure S15. The total count of bacteria in different tissues after respectively injecting Bac@Au, Bac and PBS for 24 h. 


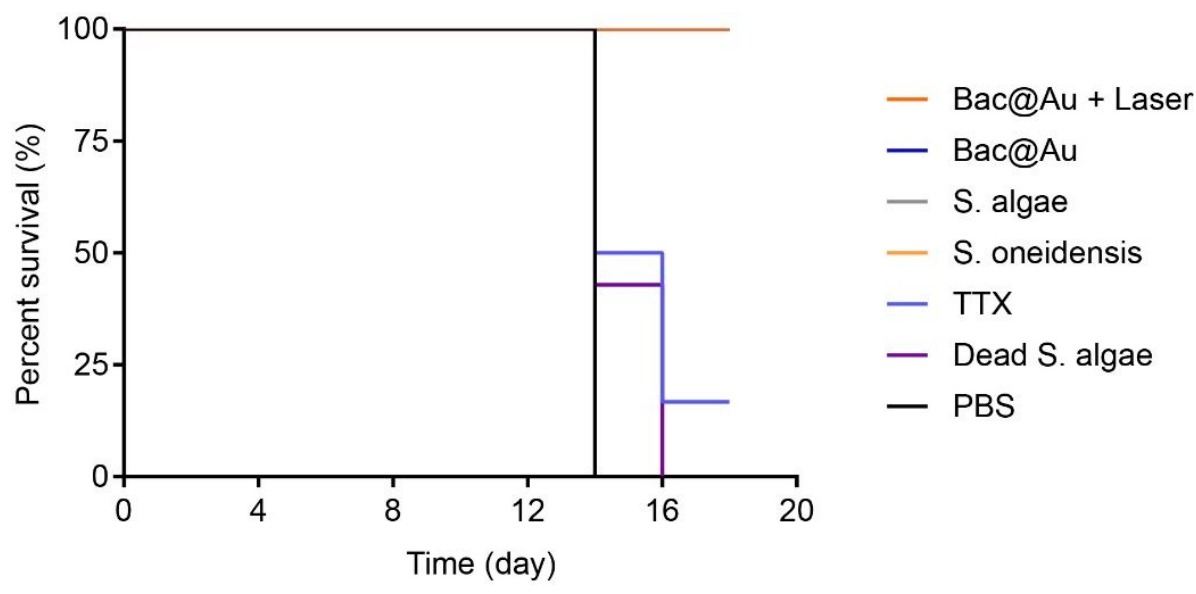

Figure S16. Living condition of mice based on the tumor volume within 16 days in different treatment groups. 


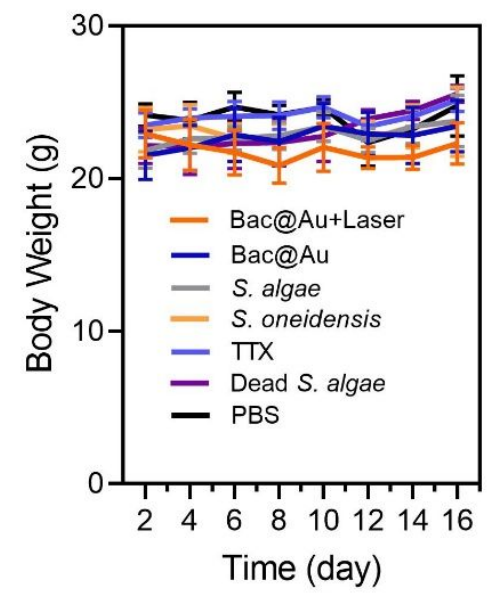

Figure S17. Body weight of mice after different treatments $(n=7)$. 


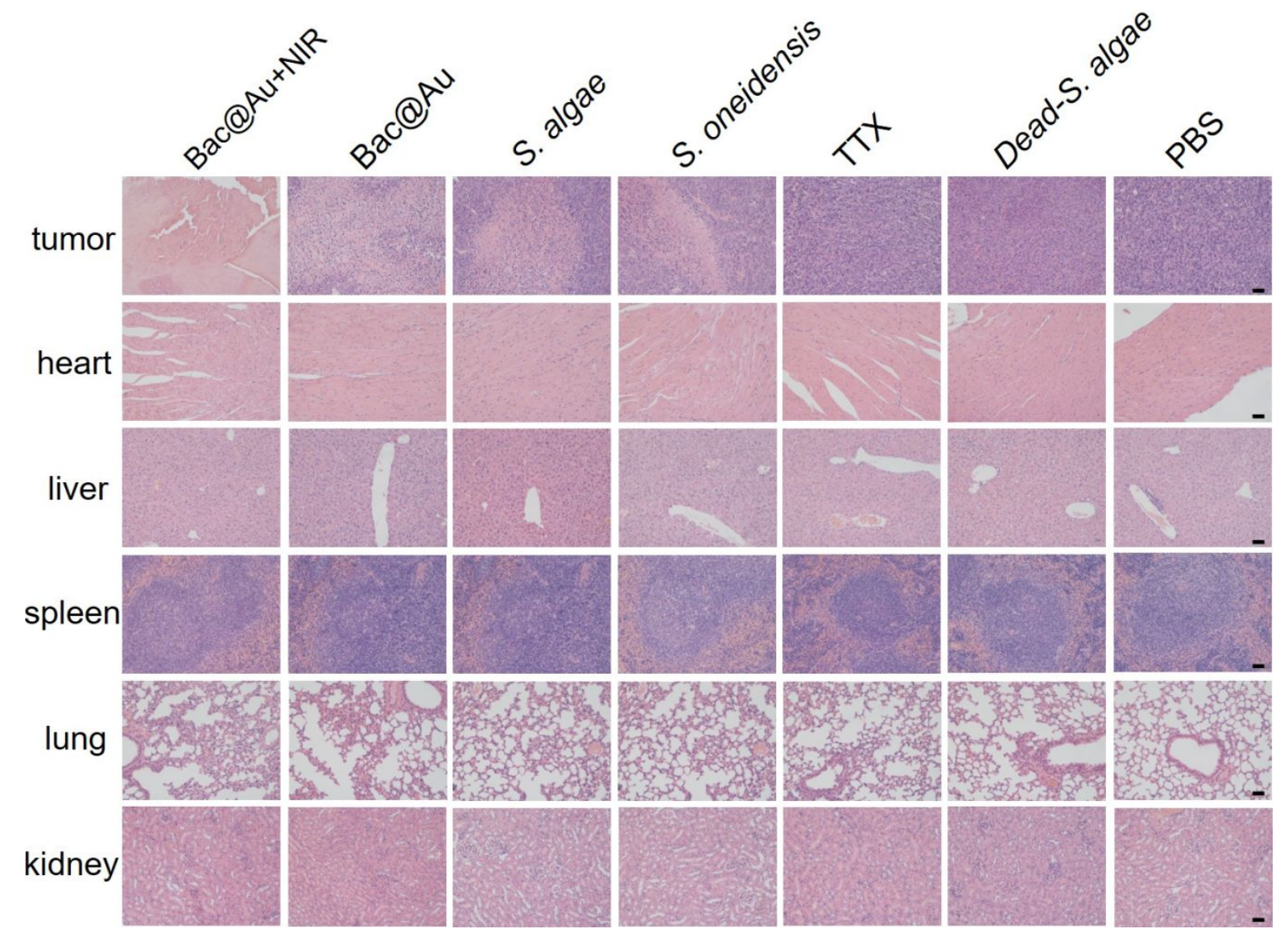

Figure S18. H\&E staining of the tumor and major organs (heart, liver, spleen, lung, and kidney) after different treatments (scale bar: $50 \mu \mathrm{m}$ ). 

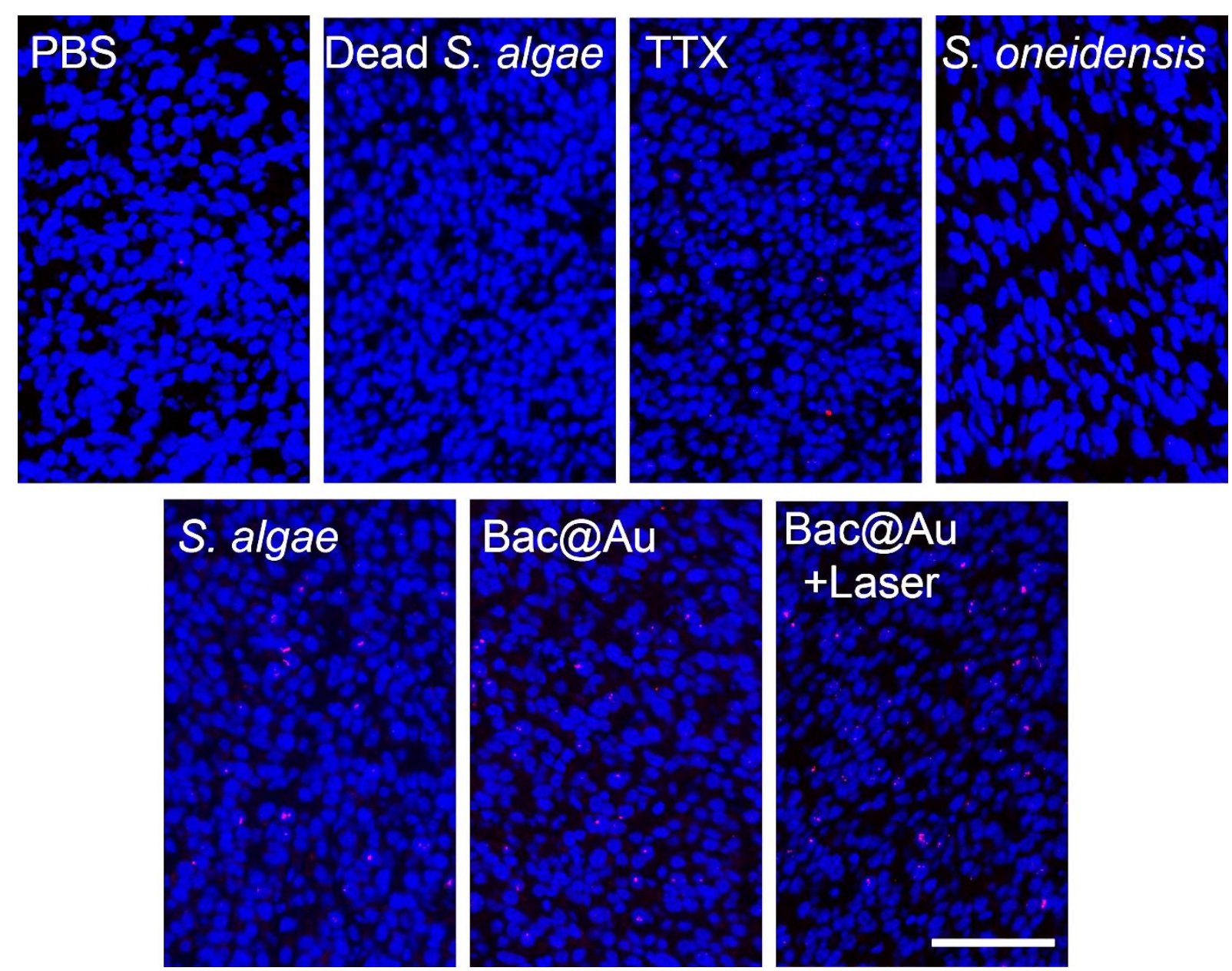

Figure S19. TNF- $\alpha$ of tumor tissues after different treatments (scale bar: $100 \mu \mathrm{m}$ ). 
A
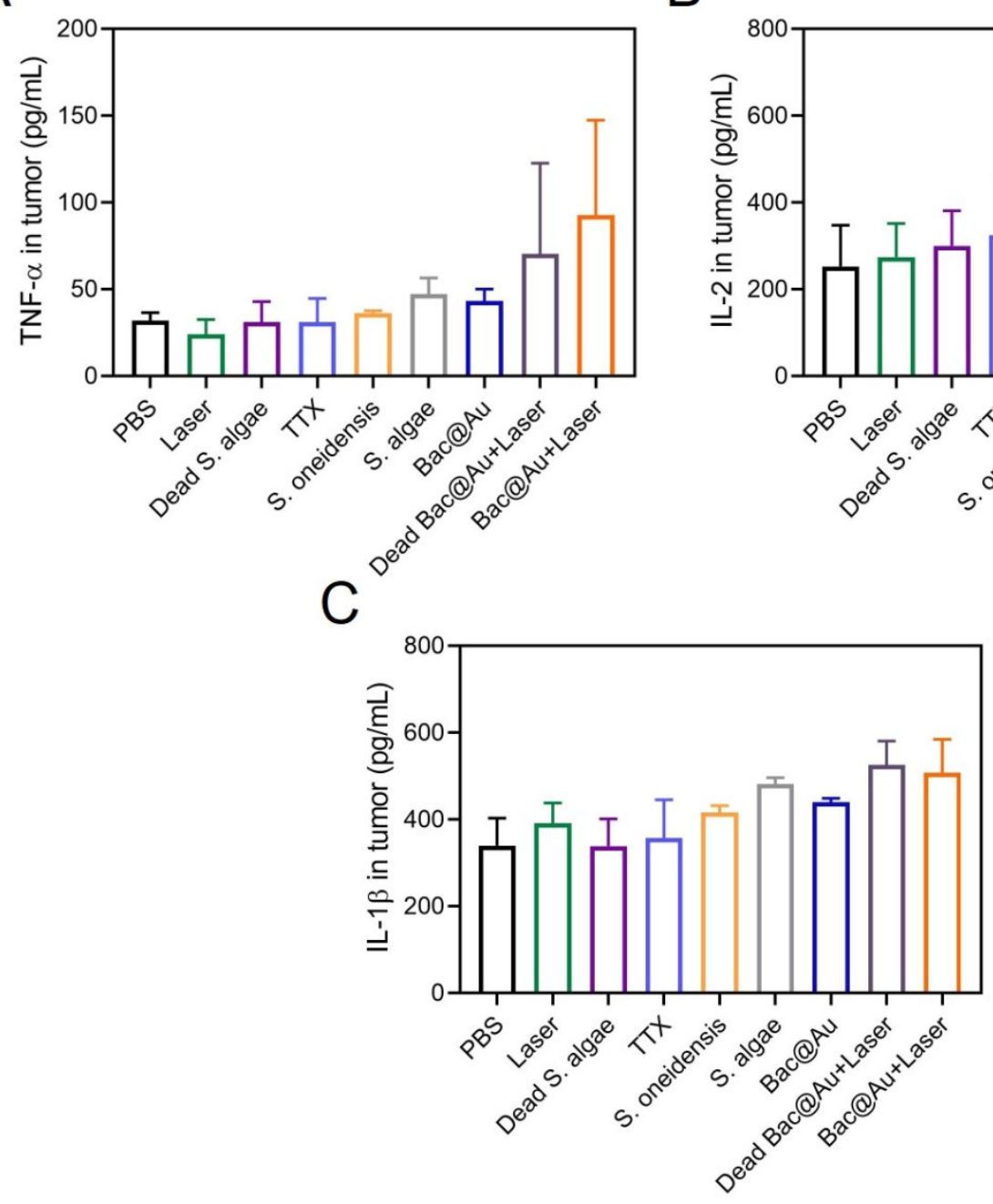

B

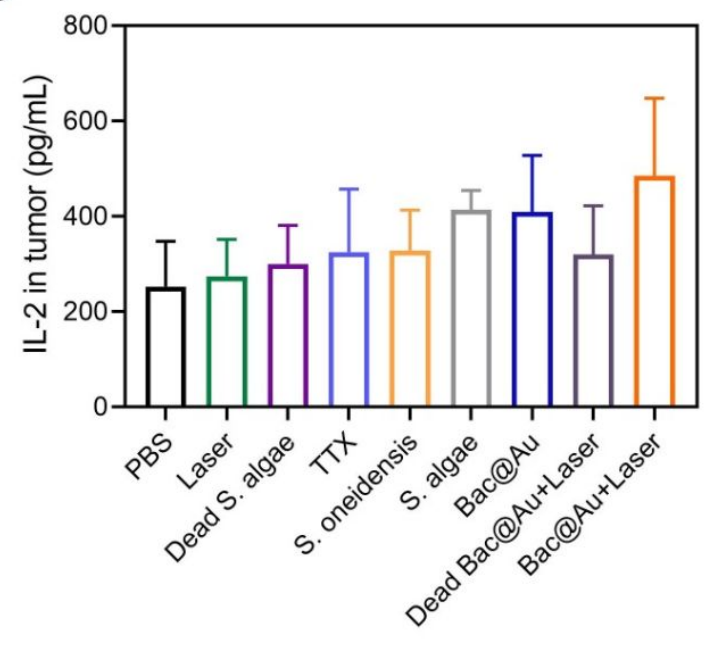

Figure S20. The expressions of (A) TNF- $\alpha$, (B) IL-2 and (C) IL-1 $\beta$ in tumor. 


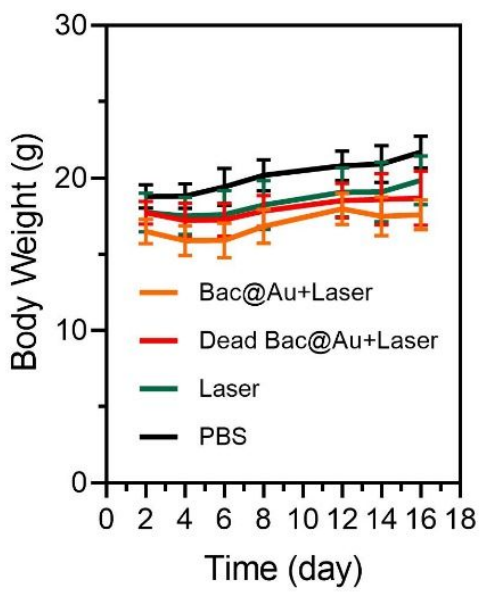

Figure S21. Body weight of mice after different treatments $(n=7)$. 


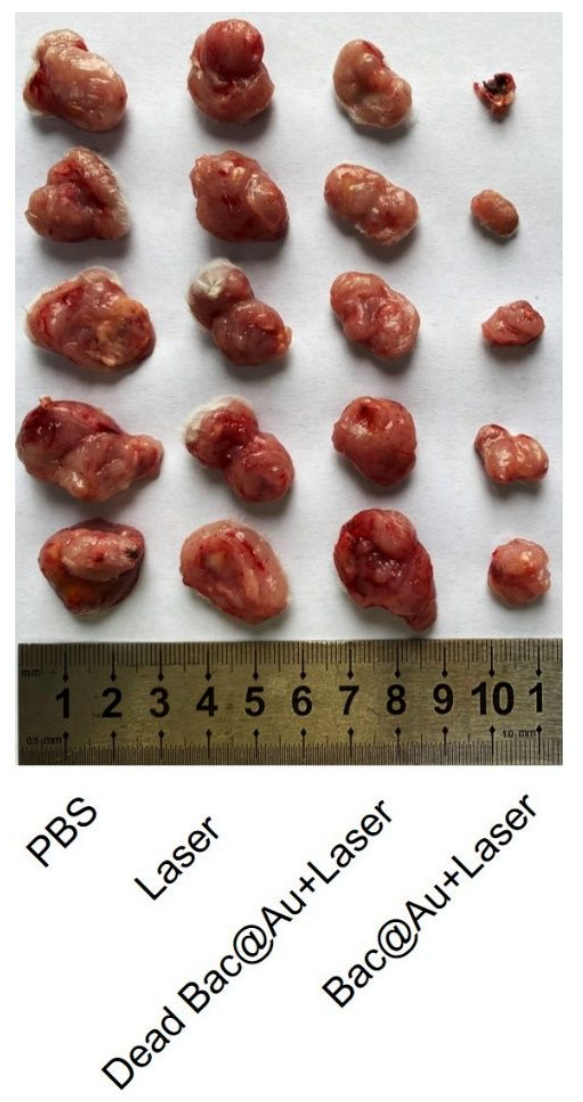

Figure S22. Corresponding photographs of harvested tumors after different treatments. 
A

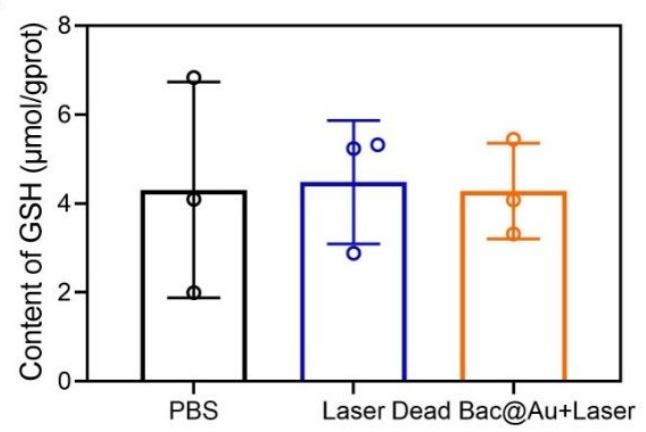

B

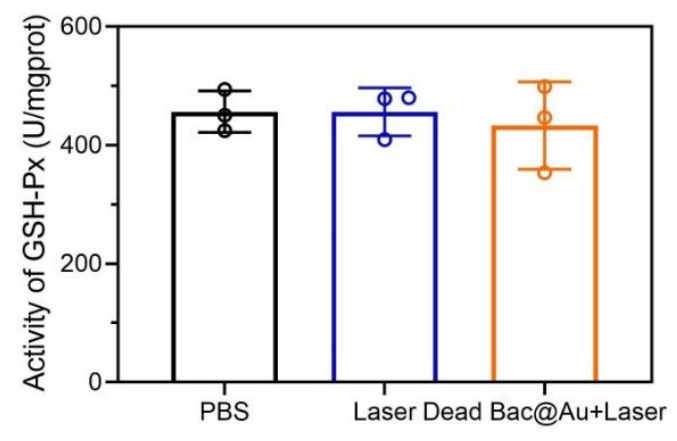

C

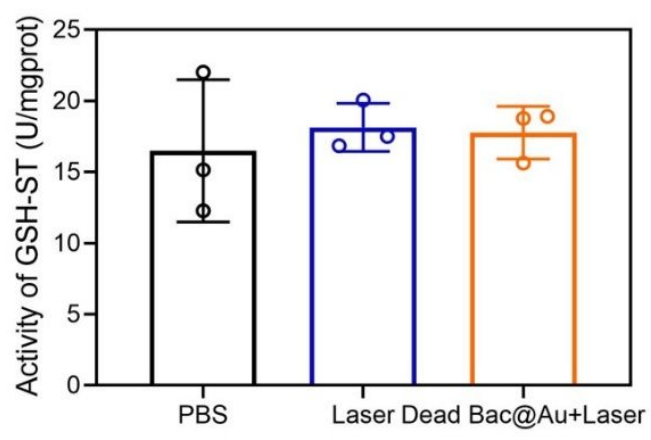

Figure S23. (A) Expression of GSH, (B) activity of GSH-Px and (C) GSH-ST in tumor tissue after different treatments $(n=3)$. 


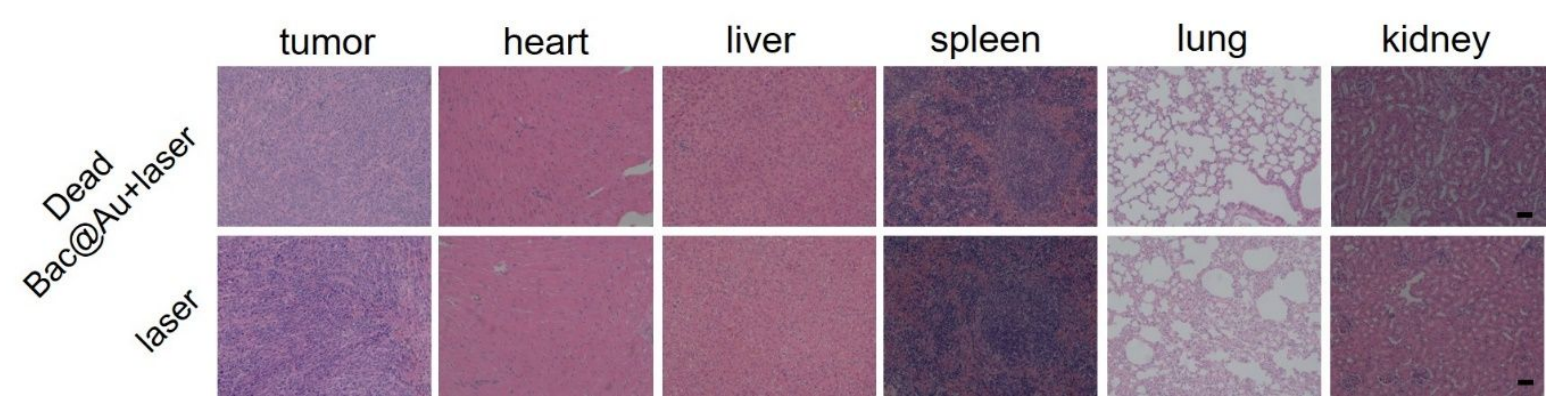

Figure S24. H\&E staining of the tumor and major organs (heart, liver, spleen, lung, and kidney) after different treatments (scale bar: $50 \mu \mathrm{m}$ ). 
A

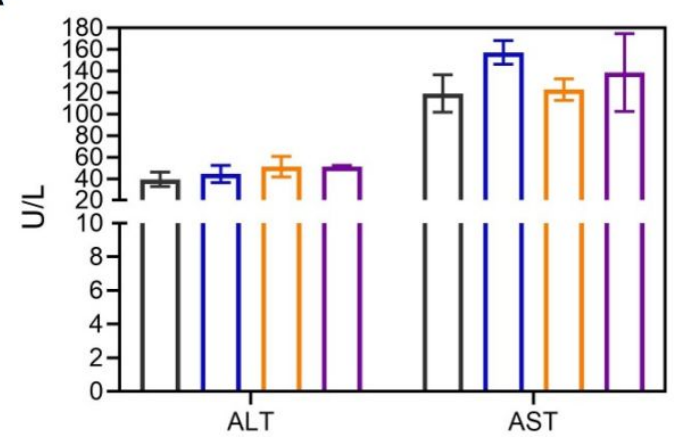

B

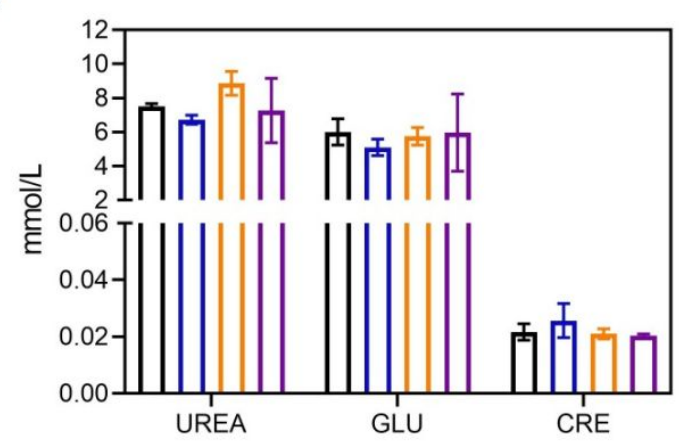

C

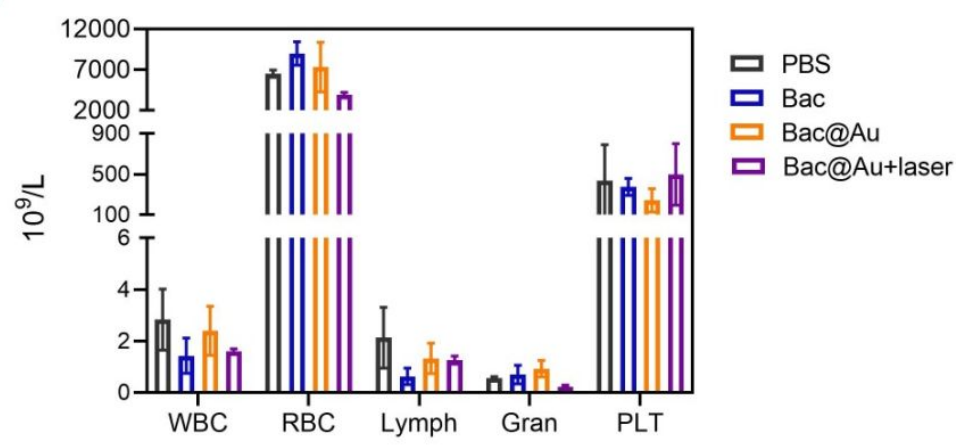

Figure S25. (A) Relate indexes of liver function such as ALT and AST after different treatments. (B) Relate indexes of kidney function such as UREA, GLU and CRE after different treatments. (C) Relate indexes of main blood cells such as WBC, RBC, Lymph, Gran and PLT in different treatment groups. 


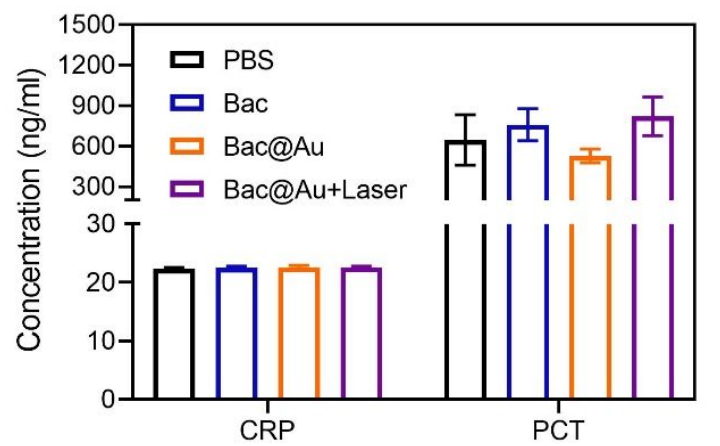

Figure S26. The concentration of CRP and PCT in plasma on the first day after different treatments. 